ORGINAL ARTICLE

\title{
SAFETY AND ANALGESIC PROPERTIES OF ETHANOLIC EXTRACTS OF TODDALIA ASIATICA (L) LAM. (RUTACEAE) USED FOR CENTRAL AND PERIPHERAL PAIN MANAGEMENT AMONG THE EAST AFRICAN ETHNIC COMMUNITIES
}

\author{
Kimang'a Andrew ${ }^{1}$, Gikunju Joseph ${ }^{2}$, Kariuki Daniel ${ }^{3}$, Ogutu Millicent ${ }^{2}$
}

\begin{abstract}
BACKGROUND: Although herbs are often perceived as "natural" and therefore safe, many different side effects have been reported. Additionally, there is limited scientific evidence to establish the safety and efficacy of most herbal products. The aim of this study was to evaluate the biochemical and haematological effects of Toddaliaasiatica (L) Lam. (Rutaceae) (T. asiatica (L.) in albino Wistar rats.

MATERIALS AND METHODS: The phytochemicals present in the plant were determined. The analgesic activity was determined using the hot plate technique. The whole blood with anticoagulant was used for assay of the haematological parameters using the COULTERAc•T5diff AL Hematology Analyzer (Fullerton, CA, USA). The biochemical parameters determined with HumaLyzer 2000, a semiautomatic, microprocessor-controlled photometer from chem-labs, Nairobi.

RESULTS: The effect of extract on serum biochemical parameters after 14 days treatment with the crude ethanolic extract of $T$. asiatica $(L$.) revealed significant difference in the Cholesterol $(P=0.041)$, alanine transaminase $(P=0.007)$, gamma-glutamyl transferase $(P=0.045)$. There was no significance in the alkaline phosphatase (ALP), aspartate transaminase (AST) levels compared to the untreated controls. Peripheral blood films (PBFs) of the treated animals were performed and stained with leishman's stain. Major morphological changes were observed including anisocytosis, burr cells, anisochromia, hypochromia and reactive lymphocytes among others.

CONCLUSION: The crude extract of T. asiatica (L.) showed better analgesic effect $(28.2 \pm 13.16)$ than Acetylsalicylate used as control (4 \pm 0.31$)$. The potential of T. asiatica (L.) asananalgesic was remarkable. However, the crude extract of $T$. asiatica $(L$.$) induced nephrotoxicity and liver enzymes modulation and$ elevated total cholesterol in the test organisms compared to the untreated negative controls.

KEYWORDS: Biochemical, Haematological, Toxicity, Phytochemicals
\end{abstract}

DOI: http://dx.doi.org/10.4314/ejhs.v25i4.10

\section{INTRODUCTION}

It is estimated that three quarters of the world population rely on herbal and traditional medicine as a basis for primary health care (1). Overreliance on herbal medicines would partly be due to unaffordability of conventional medicines and also due to many people having the mistaken belief that, being natural, all herbs and foods are safe. Herbal products have been shown to inhibit and/or induce drug-metabolizing enzymes (2). $T$. asiatica (L.) is a commonly used medicinal plant in East Africa for the management of pain and inflammatory conditions $(3,4,5,6)$. There is no scientific rationale to assume that $T$. asiatica $(L$.),

\footnotetext{
${ }^{1}$ Department of Medical Microbiology, Jomo Kenyatta University of Agriculture and Technology, Nairobi, Kenya

${ }^{2}$ Department of Medical Lab. Sciences, Jomo Kenyatta University of Agriculture and Technology, Nairobi, Kenya

${ }^{3}$ Department of Biochemistry, Jomo Kenyatta University of Agriculture and Technology, Nairobi, Kenya

Corresponding Author: Kimang'a Andrew (kinyerere@yahoo.com)
} 
its parts and/or derived products, including those of long-standing popular use, are intrinsically safe compared to conventional medicines. $T$. asiatica (L.) is a multipurpose plant species with important therapeutic values. Toddaculin isolated from of Toddalia asiatica (L.) has been found to inhibit the differentiation of osteoclasts via activation of the NF- $\kappa$ B, ERK 1/2, and p38 MAPK signaling pathways. Additionally, it induces differentiation and mineralization of osteoblasts by regulating differentiation factors (7). Ethyl acetate extract of $T$. asiatica leaves (TALEe) exert significant antidiabetic and antioxidant effects in STZinduced diabetic rats (8). Ethanolic extract of stem bark of Toddalia asiatica (L.) Lam possess effective antiinflammatory and antioxidant activity (9). In East Africa, it commonly grows in riverine and forest edge habitats from where it is harvested (10). This is an important plant used for the treatment of a wide range of diseases. Local herbalists use toddalia for medicinal purposes $(10$, 11). In this study, the ethanolic extract of $T$. asiatica leaves was evaluated for analgesic activity and safety using albino Wistar rats.

\section{METHODS}

Plant materials: This study was carried out between December 2014 and March 2015. The study used leaves of Toddalia asiatica (L) Lam. (Rutaceae). The plant was obtained from Kakamega forest in Western Kenya in the month of December 2014. The identity of the was confirmed in the Department of Botany in the School of Biological Sciences at Jomo Kenyatta University of Agriculture and Technology. The leaves were prepared and dried separately in the shade for a period of three weeks. The plant part was then pulverized to powder using a mechanical grinder. The plant extract was prepared as per the method described by Mboso et al (12). About $1 \mathrm{~kg}$ of the blended leaves was weighed out and soaked in $3000 \mathrm{~mL}$ of $95 \%$ ethanol at the ratio of $4: 1$ powder to ethanol respectively for 72 hours. It was later sieved with sieve cloth to get the liquid portion. The liquid portion was filtered with a filter paper in order to get clear filtrate. The filtrate was concentrated using a hot air oven at a regulated temperature of $40^{\circ} \mathrm{C}$. This gave rise to a crude ethanolic extract. The extract was stored at room temperature during use.
Phytochemicals analysis: The phytochemicals present in the crude ethanolic extract of $T$. asiatica (L) Lam were determined using the standard procedures and relevant reagents $(13,14)$. Test for tannins: About $0.5 \mathrm{~g}$ of each methanol extract was boiled in $20 \mathrm{ml}$ of water in their respective test tubes and then filtered. A few drops of $0.1 \%$ ferric chloride were added to each test tube. A brownish green or blue-black coloration indicated the presence of tannins. Saponins: To $400 \mathrm{ml}$ of distilled water was added to $50 \mathrm{~g}$ of powdered sample in a conical flask and boiled for $5 \mathrm{~min}$. The mixture was filtered when still hot and $5 \mathrm{ml}$ of sterile distilled water added to a test tube containing equal amounts of cooled filtrate. The test tube was shaken vigorously for 30 seconds and then allowed to stand for $30 \mathrm{~min}$. Formation of honey comb froth indicates the presence of saponins. Flavonoids: $5 \mathrm{ml}$ of dilute ammonia solution was added to a portion of the aqueous filtrate of each plant extract followed by addition of concentrated $\mathrm{H} 2 \mathrm{SO} 4$. Formation of yellow color indicated the presence of flavonoids. Terpenoids: $5 \mathrm{ml}$ of the extract was mixed with 2 $\mathrm{ml}$ of chloroform, and concentrated $\mathrm{H} 2 \mathrm{SO} 4(3 \mathrm{ml})$ carefully added to form a layer (Salkowski test). Phenols: To $2 \mathrm{ml}$ of the extract, $2 \mathrm{ml}$ of Iron III chloride was added to the solution. A deep bluishgreen solution indicated the presence of phenols. Alkaloids: To $1 \mathrm{ml}$ of the extract, concentrated sulphuric was added followed by potassium dichromate crystals. An olive-green colour indicated the presence of alkaloids.

Experimental Animals: Female wistar albino rats aged 8 to 10 weeks and weighing 150 to $200 \mathrm{~g}$ were used. The breeds were obtained from the stock in the Kenya Medical Research Institute animal house. The animals were housed in cages with food and water at JKUAT during the experiment.

Experimental design: The twenty-four albino Wistar rats were assigned into three experimental groups (low dose, medium dose and high dose rats of 6 animals each) and one control group. The control group was orally treated with $0.6 \mathrm{~mL}$ of normal saline. The experimental group was treated with $100 \mathrm{mg} / \mathrm{kg}, 150 \mathrm{mg} / \mathrm{kg}$ and $300 \mathrm{mg} / \mathrm{kg}$ body weight of T. asiatica (L.) extract daily for 14 days (2 weeks), through the same route. The concentrations administered were based on the method of Mboso et al (12). "Principles of 
laboratory animal care" (NIH publication No. 8523 , revised 1985) was followed and specific national laws where applicable.

Hot plate method in rats: Food was withdrawn 12 hours prior to drug administration till completion of experiment. The animals were weighed and numbered appropriately. After 60 minutes of drug administration, the animals were placed on the hot plate and the observations recorded at the time intervals of 90, 120 and 180 minutes. Acetylsalicylate at a dose of $100 \mathrm{mg} / \mathrm{Kg}$ was used as a positive control (15).

Blood collection: At the end of the treatment with extract, rats were anaesthetized with chloroform and blood collected from them by cardiac puncture. About Two milliliters of blood was collected in ethylene diamine tetra-acetic Acid (EDTA)-anticoagulated tubes from each animal, while another two milliliters of blood was collected in Heparin-anticoagulated tubes from each animal used for biochemical studies.

Hematological assays: The whole blood with anticoagulant was used for assay of the hematological parameters using the COULTER Ac $\bullet$ T 5diff AL Hematology Analyzer (Fullerton, CA, USA). Parameters determined were packed cell volume (PCV), Red blood cells (RBC) count, White blood cells (WBC) count, mean corpuscular Hemoglobin concentration (MCHC), mean corpuscular volume (MCV) Lymphocytes, Monocytes and Neutrophils, using standard assay kits (Roche diagnostics Ltd, United Kingdom).

Biochemical assays: EDTA blood was span with centrifuge at $5000 \mathrm{rpm}$ for 10 minutes. The sera was aspirated with clean and dry pipettes, and the biochemical parameters were determined with HumaLyzer 2000, asemi-automatic, microprocessor-controlled photometer from chemlabs, Nairobi. The parameters are Alanine-aminotransferase (ALT), Aspartate aminotransferase (AST), Alkaline phosphatase (ALP) and gammaglutamyltransferase (GGT) test

Statistical analysis: Primary data were analyzed and presented as the mean $+/$ - standard error of the mean. To determine the level of significance, the data were further analyzed using the one way analysis of variance (ANOVA). The difference in the test values versus the negative control values were proven to be statistically significant at $\mathrm{p} \leq$ 0.05 . Primary data on values of the time spent in pain behavior as recorded were used in statistical calculation.

\section{RESULTS}

Assessment on phytochemicals constituents of the extract: The ethanolics extract of $T$. asiatica (L.) leaves was evaluated for bioactive compounds. The extract showed the presence of the following bioactive substances: Tannins, saponins, flavonoids, alkaloids and Phenols (Table 1).

Effect of extract on weight of Wistar albino rats: The weight of the animals, in both the experimental and the control group was determined. There was no significant difference in the weight of the animals treated with $T$. asiatica (L.) extract compared to the negative control (Table 2).

Table 1: Phytochemical constituents found in the extract

\begin{tabular}{lll}
\hline PHYTOCHEMICALS & OBSERVATIONS & RESULTS \\
\hline Tannins & A brownish green or blue-black coloration & + \\
Phlobatannins & No deposition or precipitate & - \\
Saponnins & Formation of honey comb froth & + \\
Flavonoids & Formation of yellow color & + \\
Terpenoids & No coloration & - \\
Essential oils & A white precipitate & + \\
Phenols & A deep bluish-green solution & + \\
Alkaloids & An olive-green colour & + \\
\hline+
\end{tabular}

+ means present, - means not present 
Table 2: Effect of extract on weight (in grams) of rats treated for 14 days

\begin{tabular}{llllll}
\hline Period & Control & Lower dose & Medium dose & High dose & P-value \\
\hline Day one & $202 \pm 15.9374$ & $162 \pm 21.5407$ & $185 \pm 12.3153$ & $170 \pm 20$ & 0.4327 \\
Day three & $174 \pm 11.6619$ & $166 \pm 12.8841$ & $170 \pm 9.3095$ & $183.3 \pm 6.6667$ & 0.7481 \\
Day five & $198 \pm 13.1909$ & $182 \pm 11.1355$ & $186.7 \pm 4.2164$ & $193.3 \pm 8.8192$ & 0.701 \\
Day eight & $186 \pm 9.798$ & $178 \pm 14.6287$ & $188.3 \pm 16.0035$ & $206.7 \pm 6.6667$ & 0.5721 \\
Day eleven & $162 \pm 15.2971$ & $182 \pm 18.8149$ & $188.3 \pm 11.0805$ & $193.3 \pm 8.8192$ & 0.5181 \\
Day fourteen & $182 \pm 16.5529$ & $184 \pm 18.3303$ & $182.3 \pm 16.8655$ & $200 \pm 11.577$ & 0.8801 \\
\hline
\end{tabular}

ANOVA- Analysis of variance; SEM- Standard error of mean; \pm - plus or minus. The values are Mean \pm SEM.

Analgesic effect of crude ethanolic extracts of T. asiatica (L.) on female Wistar rats: The ethanolic extract of $T$. asiatica (L.) was evaluated for analgesic effect using the hot plate test method. Acetylsalicylate, at a dose of $100 \mathrm{mg} / \mathrm{kg}$, was used as a positive control (Table 3). Negative controls were given $0.6 \mathrm{~mL}$ of normal saline. After
60 minutes, the animals were placed on the hot plate and the observations recorded and then at the time interval of 90 and 120 minutes. Acetylsalicylate at dose of $100 \mathrm{mg} / \mathrm{Kg}$ was used as a positive control. The negative controls reacted to pain within one minute $(1 \pm 0.0000)$.

Table 3: Pain response time (in seconds) of rats treated with extracts of Toddalia asiatica (L)

\begin{tabular}{|c|c|c|c|c|c|}
\hline Period & Positive Control & Lower dose & Medium dose & High dose & P-value \\
\hline \multicolumn{6}{|l|}{ DAY 1} \\
\hline TIME 1 & $4 \pm 0.3162$ & $15.4 \pm 2.7495$ & $7.66 \pm 1.0541$ & $5.33 \pm 0.3333$ & 0.00104 \\
\hline TIME 2 & $4 \pm 0.3163$ & $5.6 \pm 1.2884$ & $4.1 \pm 0.7491$ & $4.3 \pm 0.8819$ & 0.6068 \\
\hline TIME 3 & $4 \pm 0.3164$ & $5 \pm 1.3038$ & $6 \pm 2.5854$ & $1.6 \pm 0.6667$ & 0.3458 \\
\hline \multicolumn{6}{|l|}{ DAY 2} \\
\hline TIME 1 & $4 \pm 0.3162$ & $28.2 \pm 13.1697$ & $3.1 \pm 0.9804$ & $2 \pm 0.5774$ & 0.0626 \\
\hline TIME 2 & $4 \pm 0.3163$ & $1.8 \pm 0.2$ & $2.5 \pm 0.482$ & $5 \pm 1.7321$ & 0.0108 \\
\hline TIME 3 & $4 \pm 0.3164$ & $7.6 \pm 3.1875$ & $3.3 \pm 1.3581$ & $6.3 \pm 5.3333$ & 0.6188 \\
\hline \multicolumn{6}{|l|}{ DAY 3} \\
\hline TIME 1 & $4 \pm 0.3164$ & $25 \pm 14.2899$ & $3.6 \pm 2.2901$ & $1.6 \pm 0.3333$ & 0.1729 \\
\hline TIME 2 & $4 \pm 0.3165$ & $1.2 \pm 0.3741$ & $1.5 \pm 0.2236$ & $1.6 \pm 0.3333$ & $<0.0001$ \\
\hline TIME 3 & $4 \pm 0.3166$ & $2.2 \pm 0.2000$ & $1.8 \pm 1.0677$ & $1 \pm 0000$ & 0.0357 \\
\hline \multicolumn{6}{|l|}{ DAY 4} \\
\hline TIME 1 & $4 \pm 0.3165$ & $12.8 \pm 11.8$ & $1 \pm 0000$ & $1.3 \pm 0.3162$ & 0.6384 \\
\hline TIME 2 & $4 \pm 0.3166$ & $1 \pm 0.0000$ & $1 \pm 0.0000$ & $1 \pm 0.0000$ & $<0.0001$ \\
\hline TIME 3 & $4 \pm 0.3167$ & $1.6 \pm 0400$ & $2.6 \pm 2.1858$ & $1 \pm 0.0000$ & 0.1229 \\
\hline \multicolumn{6}{|l|}{ DAY 5} \\
\hline TIME 1 & $4 \pm 0.3166$ & $1 \pm 0.0000$ & $1 \pm 0.0000$ & $2.3 \pm 0.8819$ & 0.0001 \\
\hline TIME 2 & $4 \pm 0.3167$ & $1 \pm 0.0000$ & $1 \pm 0.0000$ & $4 \pm 0.3162$ & $<0.0001$ \\
\hline TIME 3 & $4 \pm 0.3168$ & $1.2 \pm 0.2000$ & $3.5 \pm 1.3229$ & $2 \pm 0.5774$ & 0.04811 \\
\hline
\end{tabular}

T1-Time 1 (60 minutes), T2-Time 2 (90 minutes), T3-Time 3 (120 minutes)

Effect of $T$. asiatica (L.) ethanolic extract on selected serum biochemical parameters: Fourteen (14) days treatments with the crude ethanolic extract of $T$. asiatica $(L$.$) revealed$ significant difference in Cholesterol $(\mathrm{P}=0.041)$, alanine transaminase $(\mathrm{P}=0.007)$, gamma- 
glutamyl-transpeptidase $(\mathrm{P}=0.045)$. There was no significant difference in levels of alkaline phosphatase (ALP) and aspartate transaminase
(AST), between treated and untreated controls (Table 4).

Table 4: Levels of selected biochemical parameters in serum of rats treated with ethanolic extracts of Toddalia asiatica (L).

\begin{tabular}{llllll}
\hline Parameter & Control & Lower dose & Medium dose & High dose & P-value \\
\hline & & & & & \\
C (mg/dl) & $54.34 \pm 3.673$ & $81.6 \pm 10.968$ & $61.033 \pm 2.791$ & $68.733 \pm 1.17$ & 0.0409 \\
ALP (U/L) & $107.06 \pm 14.622$ & $235.8 \pm 36.15$ & $138.36 \pm 42.84$ & $129.53 \pm 11.49$ & 0.0781 \\
AST (U/L) & $257.04 \pm 16.909$ & $214.98 \pm 13.57$ & $211.3 \pm 15.356$ & $294.7 \pm 62.51$ & 0.1187 \\
ALT (U/L) & $151.52 \pm 14.264$ & $154.08 \pm 9.37$ & $112.583 \pm 4.61$ & $96.6 \pm 2.845$ & 0.0066 \\
GGT (U/L) & $3.56 \pm 0.759$ & $14.72 \pm 4.345$ & $8.4 \pm 2.249$ & $3.9 \pm 1.082$ & 0.0445 \\
\hline
\end{tabular}

Values presented are the Means \pm SEM (standard error of mean). The conversion factor for cholesterol from $\mathrm{mg} / \mathrm{dl}$ to $\mathrm{mmol} / \mathrm{l}$ is: 0.025864 .

Effect of the extract on blood parameters: There was no significant difference in total white blood cells (WBC), red blood cells (RBC) count, blood hemoglobin concentration (HB), packed cell volume (PCV), mean corpuscular volume (MCV), mean corpuscular hemoglobin $(\mathrm{MCH})$, mean corpuscular hemoglobin concentration (MCHC), platelets (PLTs), Neutrophils (NEUT), lymphocytes (LYMP), monocytes (MON), eosinophils (EOS) and basophils (BASO) between treated and untreated groups (Table 5). The values are Mean \pm SEM. Animals received doses orally for 14 days. Peripheral blood films (PBFs) of the treated animals were performed and stained with leishman stain. Major morphological changes were observed including anisocytosis, burr cells, anisochromia, hypochromia and reactive lymphocytes among others.

Table 1: Haematological parameters of rats treated with the extracts of Toddalia asiatica

\begin{tabular}{llllll}
\hline Parameter & Control & Lower dose & Medium dose & High dose & P-value \\
\hline WBC $\left(\right.$ X 10 $\left.0^{3} \mu \mathrm{l}\right)$ & $3.8167 \pm 1.8609$ & $6.62 \pm 2.7211$ & $3.9333 \pm 1.9472$ & $4.18 \pm 1.8609$ & 0.755 \\
RBC $\left(\right.$ X $\left.10^{6} \mu \mathrm{l}\right)$ & $5.2533 \pm 1.7009$ & $3.942 \pm 1.6423$ & $3.5367 \pm 1.6012$ & $4.662 \pm 1.910$ & 0.895 \\
HB $(\mathrm{g} / \mathrm{dl})$ & $7.9333 \pm 3.5521$ & $7.84 \pm 3.2632$ & $6.9833 \pm 3.1604$ & $9.04 \pm 3.5521$ & 0.980 \\
PCV $(\%)$ & $24.2167 \pm 10.8429$ & $23.34 \pm 9.7237$ & $20.95 \pm 9.4857$ & $27.36 \pm 11.224$ & 0.980 \\
MCV (fl) & $29 \pm 12.9795$ & $35.4 \pm 14.4554$ & $29.6667 \pm 13.2707$ & $35 \pm 14.2899$ & 0.980 \\
MCHC (g/dl) & $16.3833 \pm 7.3295$ & $20.18 \pm 8.2386$ & $16.6333 \pm 7.4394$ & $19.84 \pm 8.1$ & 0.975 \\
MCH (pg) & $9.4667 \pm 4.2415$ & $11.96 \pm 4.8843$ & $9.8667 \pm 4.4216$ & $11.64 \pm 4.753$ & 0.975 \\
RDW (\%) & $5.15 \pm 2.3036$ & $7.28 \pm 2.9808$ & $6 \pm 2.6881$ & $6.92 \pm 2.8445$ & 0.941 \\
PLTs ( X 10 $\left.{ }^{3} \mu 1\right)$ & $287.334 \pm 132.6757$ & $428.8 \pm 197.8803$ & $370.333 \pm 166.7688$ & $402.4 \pm 167.5717$ & 0.935 \\
NEUT (\%) & $12.033 \pm 5.3977$ & $11.9 \pm 4.8616$ & $13.1 \pm 5.9641$ & $12.76 \pm 5.3977$ & 0.999 \\
LYMP (\%) & $31.6 \pm 14.1708$ & $39.36 \pm 16.1486$ & $29.5667 \pm 13.2788$ & $41.84 \pm 17.1466$ & 0.928 \\
MON (\%) & $3.85 \pm 1.9609$ & $6.06 \pm 2.7716$ & $4.35 \pm 2.1857$ & $3.94 \pm 1.6213$ & 0.881 \\
EOS (\%) & $2.03 \pm 1.1083$ & $1.4 \pm 0.5761$ & $2.18 \pm 1.2708$ & $0.96 \pm 0.4632$ & 0.804 \\
BASO (\%) & $0.48 \pm 0.2257$ & $1.28 \pm 0.7517$ & $0.47 \pm 0.2106$ & $0.72 \pm 0.3513$ & 0.485 \\
\hline
\end{tabular}




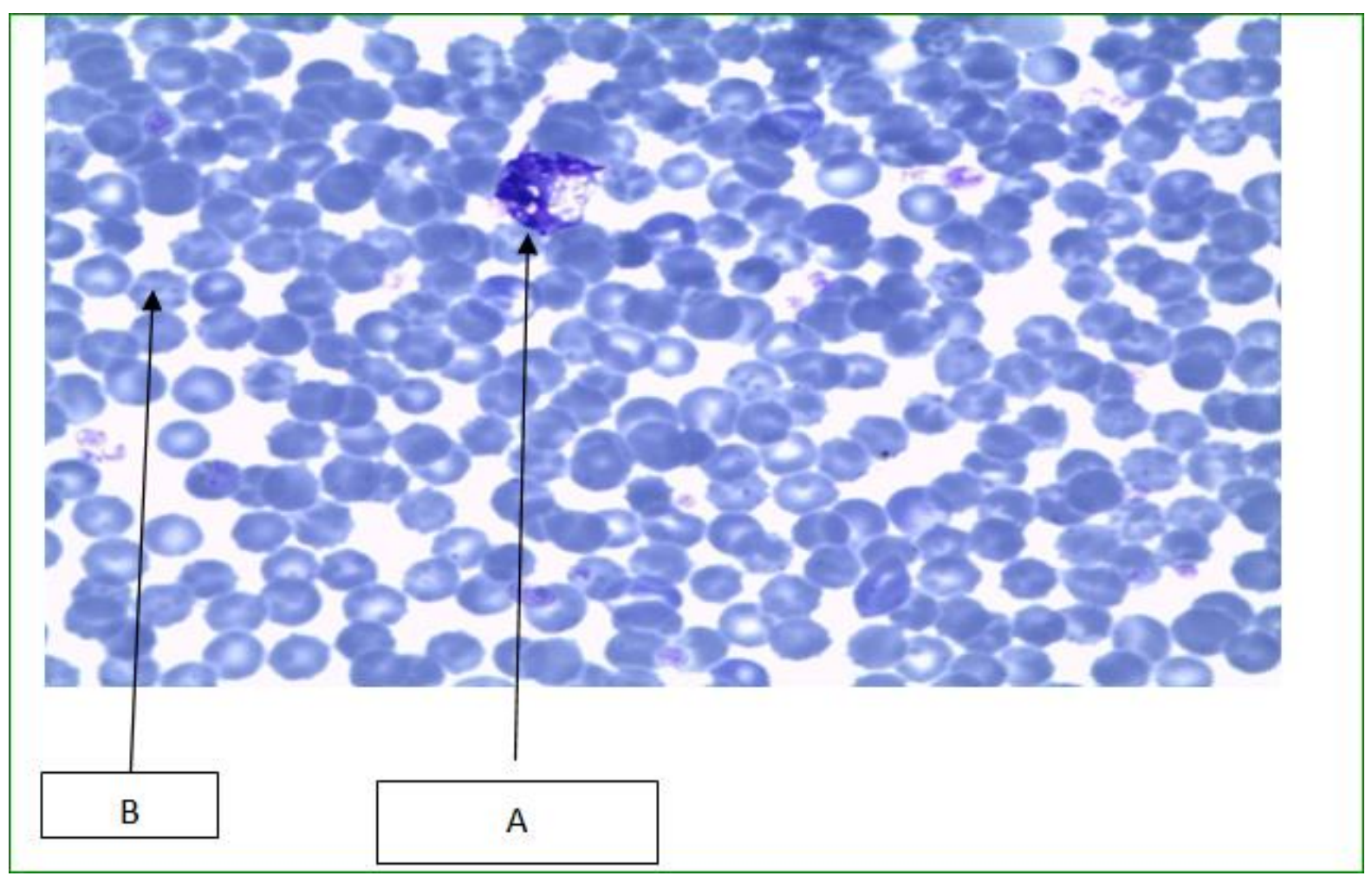

Figure 1: Photomicrograph of the blood cells with abnormal morphologies caused by consumption of crude extract of $T$. asiatica (L.) for 14 days

The micrographs show reactive lymphocytes (A). These are lymphocytes that become large as a result of antigen stimulation. Typically they can be more than $30 \mu \mathrm{m}$ in diameter with varying size and shape. It also shows the presence of Burr cells (B), referring to a form of red blood cell that has an abnormal cell membrane characterized by many small, evenly spaced thorny projections.

\section{DISCUSSION}

The ethanolic extract of the leaves $T$. asiatica in this study showed the presence of Tannins, saponins, flavonoids, alkaloids and Phenols but not terpenoid, Phlobatannins and Essential oils. Previous qualitative phytochemical screening of $T$. asiatica (L.) leaves with; methanolic, water, petroleum ether and chloroform extraction showed the presence of carbohydrates, proteins, flavonoids, steroids, phenols, saponins, terpenoids, resins and tannins in methanolic and water extracts. Petroleum ether and chloroform did not show the presence of steroids. Alkaloids and glycosides were not present in any solvent (16). It can be noticed that this study is at variance with the study by Rachael et al. (16). The current study established the presence of alkaloids but not terpenoids in addition to the other phytochemicals while the study by Rachael et al. (16) established the presence of terpenoids but not alkaloids. It is important to note that the Rachael study investigated the whole aerial parts of the plant $T$. asiatica $(L$. $)$ while this study investigated only the leaves and this may explain the presence of terpenoids. The absence of the alkaloids in this study however could be due to the different geographical localities where the plant was growing. The current study obtained the plants from Kakamega forest in western Kenya whereas the study by Rachael et al. (16) obtained them from the Nilgiris districts of Tamil Nadu, India. It in other studies, it was found out that environmental factors have slight effects on the phytochemical content of same plants in different locations (17).

There was no significant difference in the weight of the animals treated with $T$. asiatica $(L$.) extract compared to the negative control (Table 2). Administration of extracts of $T$. asiatica $(L$.) for 14 days produced no clinical signs for toxicity or mortality. In addition, the treated rats did not show any significant alteration in water or food 
consumption. According to Kwan et al. (18), significant reduction in food and water intake is suggested as being responsible for the observed decrease in body weight. Loss of appetite is often synonymous with weight loss due to disturbances in carbohydrate, protein or fat metabolisms (19). Moreover, at higher doses, crude plant extracts may metabolise to toxic end product, which could interfere with gastric function and decrease food conversion efficiency (20). Interestingly, the food and water intakes were found unaltered during the 90-day treatment period compared to a control group in the study by Kwan et al. (18). Furthermore, the diets and water were wellaccepted by the rats treated with $T$. asiatica $(L$.) extract. This suggests that the extract did not possibly cause any alterations in carbohydrate, protein or fat metabolism in these experimental animals. It also shows that the $T$. asiatica (L.) extract did not adversely interfere with the nutritional benefits, such as weight gain and stability of the appetite, which are expected for animals that are continually supplied with food and water ad libitum.

The ethanolic extract of $T$. asiatica (L.) was evaluated for analgesic effect using the hot plate test method. Acetylsalicylate at a dose of $100 \mathrm{mg} / \mathrm{kg}$ was used as a positive control (Table $3)$. The finding in the present study corroborated with Hao et al. $(21,3)$. This demonstrates that crude extract of $T$. asiatica (L.) has analgesic potential better than Acetylsalicylate used as a positive control.

The effect of $T$. asiatica (L.) extract on serum biochemical parameters after 14 days revealed significant difference in the levels of Cholesterol $(P=0.041)$, alanine transaminase $(P=0.007)$ and gamma-glutamyltranspeptidase $(\mathrm{P}=0.045)$. There was however no significant difference in levels ofalkalinephosphatase (ALP) and aspartate transaminase (AST) between treated and untreated groups (Table 5).Total cholesterol (TC) and lowdensity lipoprotein cholesterol (LDLC) levels are positively related to coronary heart disease (CHD), and high-density lipoprotein cholesterol (HDLC) levels are negatively related to CHD (22).

Increased liver alkaline phosphatase or gamma-glutamyltransferase activity suggests that direct or indirect induction of select hepatobiliary injury markers can occur. This happens both in the absence of liver injury and independently of induction of hepatic drug-metabolizing enzyme (DME) activity. Increases in serum/plasma activities that are substantial or involve changes in other markers generally reflect hepatobiliary insult rather than DME induction (23). In this study, ALT values were decreased compared to the controls while GGT was elevated compared to the control group. This could mean that the plant has both a selective hepatobiliary injury and induction of hepatic drug-metabolizing enzyme (DME) activity.

An evaluation of the blood parameters showed no significant difference in the treated groups (Table 5). However, peripheral blood films (PBFs) indicated that the plant extract could have effects on the blood cells. For instance, burr cells, anisocytosis, hypochromia and anisochromia were observed in the majority of the smears, while a few smears showed reactive lymphocytes. Complete blood counts are done to monitor overall health, to screen for some diseases, to confirm a diagnosis of some medical conditions, to monitor a medical condition and to monitor changes in the body caused by medical treatments (24).

PBFs of the animals showed significant burr cells. The presence of burr cells (echinocytes) may indicate abnormally high level of nitrogen waste products in the blood (25). Another significant finding was anisochromasia. Anisochromasia or anisochromia is the non-uniform color of erythrocytes caused by a non-uniform distribution of hemoglobin in them. Slight anisochromasia is normal due to the biconcave shape of erythrocytes; if excessive, it can point to forms of anemia that are caused by a deficiency of iron. Herbal medication utilization is common in many cultural groups. Because these products are unregulated, the potential for significant toxicity exists. An earlier study by Nelson et al., (26) reported a case of aplastic anemia associated with the use of an herbal medication by a 12 -year-old boy. On analysis, the herbal medication was found to contain phenylbutazone, which has been strongly associated with the production of similar hematologic abnormalities (26).

Most thin smears prepared from blood of Wistar rats fed on crude ethanolic extracts of $T$. asiatica (L.) showed anisocytosis. Anisocytosis is a medical term which means that the red blood cells are of unequal size. This is commonly found 
in anemia and other blood conditions. The red cell distribution width (RDW) is a measurement of anisocytosis (27).

A case report by Martin et al. (28) of a 39year-old Sri Lankan man, resident in Switzerland for 15 years, best describes the toxic effects of herbal products on blood and biochemical parameters. The patient presented to the emergency department with constipation and abdominal pain from which he had suffered intermittently during the previous weeks. On physical examination, the abdomen was soft without tenderness or organomegaly. An abdominal X-ray confirmed stool retention without perforation or bowel obstruction. Laboratory testing revealed a haemoglobin level of $9.1 \mathrm{~g} \mathrm{dl}^{-1}$ with normal indices and elevated reticulocytes. The blood film showed poikilocytosis, polychromasia, anisocytosis and basophilic stippling. Liver enzymes, bilirubin and LDH were mildly elevated. Haptoglobin was undetectable and the Coombs test was negative. On repeated questioning, the patient admitted having taken five ayurvedic pills per day for 2 months, until the end of December 2009, to increase his fertility. Leftover pills were examined at the Official Food Law Enforcement Authority, where concentrations up to $7.3 \mathrm{mg}$ of lead per pill and traces of arsenic, chromium and mercury were found.

Lead from 'herbal medicines', especially from Asian countries, is an emerging source of heavy metal poisoning. The blood lead concentration correlated with the symptoms at presentation. Lead concentrations below $50 \mu \mathrm{g}$ $\mathrm{dl}^{-1}$ may cause symptoms such as asthenia, arthralgia, hypertension, headache and even infertility $(29,30)$. Above these concentrations, abdominal colics, kidney dysfunction, haemolyticanaemia and encephalopathy may occur. Much of the toxicity of lead can be attributed to interference with calcium-mediated signaling or the distortion of enzymes and structural proteins, in this case leading to symptoms of acute porphyria by impairing enzymes of porphyrinbiosynthesis (31).

Evidently, T. asiatica (L.) has analgesic properties better than aspirin. Despite this encouraging finding, the crude extracts have adverse effects to the blood and liver functions. It is therefore expedient to advise that caution should be exercised in the use of $T$. asiatica (L.) in treatment of pain to avoid overdosing. This is because thre is no guidelines on standardized dosing in herbal medicine due to paucity of information on pharmaco-genetics and pharmacodynamics of herbal preparations. In addition, consideration should be given to the potential toxicity of ingesting $T$. asiatica $(L)$.

\section{REFERENCES}

1. Efferth T, Kaina B.Toxicities by herbal medicines with emphasis to traditional Chinese medicine. Curr Drug Metab, 2011; 12 (10): 989-96.

2. Davyson LM, Sabrina ST, Maria HD. Monteiro, Ana CA.X, Francisco J.R. Traditional use and safety of herbal medicines. Rev Bras Farmacogn, 2014; 24(2): 248-257.

3. Kariuki HN, Titus IK, Abiy Y, Nilesh P, Paul MM. Antinocieptive and anti-inflammatory effects of T. asiatica (L) Lam. (Rutaceae) root extract in Swiss albino mice. Pan African Medical Journal, 2013; 14: 133. doi:10.11604/pamj.2013.14.133.2130

4. Orwa JA, Jondiko IO, Minja RJA, Bekunda M. The use of Toddalia asiatica (L) Lam. (Rutaceae) in traditional medicine practice in East Africa. Journal of Ethnopharmacology, 2008; 115(2): 257-262.

5. Kokwaro JO. 1993. Medicinal Plants of East Africa. East African Literature Bureau, Nairobi.1993: 212.

6. Glover PE, Stewart J, Gwynne MD. Maasai and Kipsigis notes on East African plants. Part III. Medicinal uses of plants. East African Agricultural and Forestry Journal, 1966; 32(2):200-207.

7. Akio W, Momochika K, Takashi M, Junya I, Yurika O, Teppei H, Tsuyoshi K, Mikihiko Y, Misora S, Izumi Y, Kazuhiro F, Masatoshi W, Kiyotaka N, Teruo M. Toddaculin Isolated from of Toddalia asiatica (L.) Lam., Inhibited Osteoclastogenesis in RAW 264 Cells and Enhanced Osteoblastogenesis in MC3T3-E1 Cells. PLoS One, 2015; 10(5): e0127158. doi: 10.1371/journal.pone. 0127158

8. Stephen IS, Sunil C, Duraipandiyan V, Ignacimuthu S. Antidiabetic and antioxidant activities of Toddalia asiatica (L.) Lam. leaves in streptozotocin induced diabetic rats. $J$ 
Ethnopharmacol, 2012;143(2):515-23. doi: 10.1016/j.jep.2012.07.006. Epub 2012 Jul 27.

9. Balasubramaniam A, Manivannan R, Paramaguru R, Papiya Mitra Mazumder. Vijayakumar M. Evaluation of Antiinflammatory and Antioxidant Activities of Stem Bark of Toddalia asiatica (L.) Lam. using Different Experimental Models. Pharmacologia, 2012;3(5):144-149.

10. Nabwami J, Tabuti J, Bekunda M. Characterization of the natural habitat of $T$. asiaticain the Lake Victoria basin: soil characteristics and seedling establishment. African Crop Science Conference Proceedings, 2007; 8: 2057-2061.

11. Kariuki HN, Titus IK, Abiy Y, Nilesh BP, Mbugua PM.. Antinocieptive activity of $T$. $\operatorname{asiatica}(\mathrm{L})$ Lam. in models of central and peripheral pain. Phytopharmacology, 2012; 3(1):122-129.

12. Mboso OE., Odey MO., Uboh FE., Essien NM., Chidinma O, Eyong EU. Erythropoietic Effects of Eremomastax polysperma Leaf Extracts on Female Prepubertal and Pubertal Wistar Rats. British Journal of Pharmaceutical Research, 2014;4(15): 1833.

13. Sheila MM, Godeliver AK, Fatuma F. Documentation and Phytochemical Screening of Traditional Beauty Products Used in Missenyi District of Tanzania. Journal of Cosmetics, Dermatological Sciences and Application, 2014; 4: 355-364.

14. Ahumuza T. and Kirimuhuzya C. Qualitative (Phytochemical) Analysis and Antifungal Activity of Pentas decora (De Wild), a Plant Used Traditionally to Treat Skin Fungal Infections in Western Uganda. Research in Pharmaceutical Biotechnology, 2011; 3; 7584.

15. Onzago RO, Kiama SG, Mbaria JM., Gakuya DW, Githiji CG., Rukenya ZM. Analgesic activity of aqueous extract of Vernonia hymenolepis (A. Rich) a traditional medicine plant used in Kenya for toothache. The Journal of Phytopharmacology, 2013; 2(6): 41-45.

16. Rachael C, Seethalakshmi MS, Shubharani R, Sivaram V, Ganti S. Murthy and Ruben Michael Ceballosa. Evaluation of phytochemicals and in vitro antioxidantstudies of Toddalia asiatica leaf. Medicinal Plants, 2013; 5(4): 202-205.

17. Borokini TI., Ayodele AE. Phytochemical Screening of Tacca Leontopetaloides (L.) Kuntze Collected from Four Geographical Locations in Nigeria. International Journal of M odern Botany, 2012; 2(4): 97-102.

18. Kwan YP, Ibrahim D, Yeng C, Subramaniam S, Sreenivasan S. Acute and Subchronic Toxicity Study of Euphorbia hirta L. Methanol Extract in rats. 2013: Biomed Res Int. 2013;2013:182064. doi: 10.1155/2013/182064. Epub 2013 Dec 10.

19. Klaassen CD. Casarett and Doull's Toxicology: The Basic Science of Poisons. New York, NY, USA: McGraw-Hill Press; 2001.

20. Chokshi D. Subchronic oral toxicity of a standardized white kidney bean (Phaseolus vulgaris) extract in rats. Food and Chemical Toxicology. 2007; 45(1):32-40.

21. Hao XY, Peng L, Ye L, Huang NH, Shen YM. A study on anti-inflammatory and analgesic effects of alkaloids of Toddalia asiatica. Zhong Xi Yi Jie He Xue Bao, 2004; (6):450-2.

22. Sblendorio, V. Palmieri B. Accuracy of analyses for lipid profile parameters as measured with the CR3000 system. European review for medical and pharmacological sciences, 2008; 12: 191-196.

23. Daniela E, Dana W, Frances C, Michal M , David L, Mark G, Suzanne B, Laura B. Effects of Hepatic Drug-metabolizing Enzyme Induction on Clinical Pathology Parameters in Animals and Man. Toxicologic Pathology, 38: 810-828, 2010.

24. Mayo Clinic (14 February 2014). "Complete blood count (CBC) Why it's done - Tests and Procedures". mayoclinic.org. Retrieved 29 July 2014.

25. Bain BJ. The peripheral blood smear. In: Goldman L, Schafer AI, eds. Goldman's Cecil Medicine. 24th ed. Philadelphia, PA: Elsevier Saunders; 2011:chap 160.

26. Nelson L, Shih R, Hoffman R.Aplastic anemia induced by an adulterated herbal medication. $\mathrm{J}$ Toxicol Clin Toxicol. 1995; 33(5):467-70.

27. Barbara J. Bain. Blood cells: a practical guide. Wiley-Blackwell. 2006:66. ISBN 9781-4051-4265-6. 
28. Martin T, Alessandro C, Marianne M, Andreas L, Geneviève F. Haemolytic anaemia and abdominal pain - a cause not to be missed. Br J Clin Pharmacol, 2011; 72(1): 168-169.

29. Doumouchtsis KK, Doumouchtsis SK, Doumouchtsis EK, Perrea DN. The effect of lead intoxication on endocrine functions. $\mathbf{J}$ Endocrinol Invest. 2009; 32:175-83.

30. Needleman H. Lead poisoning. Annu Rev Med, 2004; 55:209-22.

31. Hiroyoshi F. Lead, chemical porphyria and heme as biological mediator. Tohoku J Exp Med, 2002;196:53-64. 